\title{
An Appraisal of Household Domestic Energy Consumption in Minna, Nigeria.
}

\author{
1, Abd'razack, N.T.A., ${ }^{2,}$ Medayese, S.O., ${ }^{3,}$ Matins, V. I. ${ }^{4,}$ Idowu, O .O, ${ }^{5,}$ \\ Adeleye B.M, ${ }^{6}$, Bello, L.O \\ 1, 2, 3,4,5,6 Department of Urban and Regional Planning, Federal University of Technology, Minna
}

\begin{abstract}
One of the characteristics of African cities is uncoordinated urbanization with a trend of $4 \%$ annually, but the rate differs according to regions. Several factors are associated with urbanization such as lifestyle, consumption habit and pattern. The environment today is facing challenges from urbanization as consumption of resources such as land; water; energy, and air have changed to artificial environment. Energy consumption has been the driving force in global warming. Overtime, urbanization has been a great threat to sustainability of urban environment. However, kerosene and LPG that are supposed to be the major source of energy for cooking becomes unaffordable to low income households. This research was conducted in two residential areas of the identified neighbourhood and the choice of this neighbourhood is influenced by the fact that the phenomenon under study is more prevalent in the high and medium density localities. The effect of increase in electricity tariff, kerosene and LPG has shifted the focus of household source of cooking energy to biomass and this has been the cause of the environmental problems in the area which includes Indoor Air Pollution, Deforestation and Desertification. The analysis however shows a significant relationship between choice of energy and income.
\end{abstract}

Keywords: Deforestation; Energy Consumption, Households; Environment; Urbanization.

\section{Introduction}

The major characteristics of African cities have been urbanization from the early 1950s. There are only about $11 \%$ of Africans in urban area in 1950s and this has risen to about $37.9 \%$ in year 2000 (UN-Habitat, 2008). This urbanization trend implies that by $2015,46.15 \%$ of African will be in cities. Though the recent publication by UN-Habitat estimated that the world break in term of population globally (50\% rural and urban) in 2007 (UN-Habitat, 2008). There has been high percentage of urbanization in Africa than any part of the world. The trend is about $4 \%$ averages, but the rate of population increase differs according to regions and urban and rural area. The National Population Commission (NPC) indicated that the national average is about 3.2\%, though the urban areas have higher percentage than rural areas in Nigeria (NPC, 2010). Also there are differences in urbanization in different parts of Nigeria; while it is higher in the north it is lower in the south.

There are several factors that are associated with urbanization such as lifestyle, consumption habit and pattern etc. which all have consequential effect on the environment. This process has made resources to be collected, distributed and used. Though the process according to Ecological Footprint shows that Africa is consuming lower resources but that does not mean that Africans should be complacent as poverty and population growth have tendency of consuming the resources (Clancy, 2008). GFN (2010) has proven that some cities have Ecological Footprint higher than the world average and has been compensated by other areas where consumption is lower. One of the major problems of the environment today is urbanization as consumption of resources such as land, water; energy, air etc. have changed the environment and brought about artificial environment. Energy consumption has been the driving force in global warming as Carbon emission has gone beyond the world ecological limit. Urbanization has been a threat to sustainability of urban environment because it depends on productivity of the neighbourhood, households and individuals. Nigeria with her population of over 150 million is the most populous Black Country in the world has urbanization process that is higher. By the year 2050, her population will be 250 million (UN-Habitat, 2010). The process of urbanization in Nigeria has its own antecedents, the national growth rate ranges between 2.9\% and 3.2\% between 1991 and 2006 but the urban growth rate within this period ranges between $4.8 \%$ and $5.7 \%$ (NPC, 2010). The population figure indicated that urban population was about $23.4 \%$ in 1970 and by year 2000 rose to about $43.3 \%$ and with the current trend, it will be about $61.6 \%$ by the year 2025 (UN-Habitat, 1996).

There have been many problems associated with this rapid urbanization such as manageability, livability, security threat, serviceability and stiff competition for land, long distance to work, congestion and inadequate urban infrastructure including housing, water and energy. Environmental degradation has also 
become a factor of urbanization as proper planning is lacking in the use of land and resources which occurs due to human activities on the environment: consumption of fossil fuel, deforestation, industrialization, excessive consumption of natural resources etc. due to population explosion.

Households have been affected greatly by the economic cul-de-sac and global economic meltdown and this has changed the household's ability to provide adequate shelter, energy use and services. One of the factors that contribute to the rapid urban growth in Nigeria was the oil boom of the 1970s. The fall in the oil price at the world market has had untold hardship on households and government have introduced several austerity measures such as Structural Adjustment Programme (SAP), control on importation and removal of subsidy. 80\% of the oil subsidy was removed in 1986 (Ojo, 1989) the trend has continued with the present dispensation that has increased the cost of petroleum product since year 2001 till date. The latest removal has increase the pump price of petrol by about 50\%. All these increases instead of controlling the system help in perpetuating the sufferings of the poor households in urban areas. For example, there was negative growth in consumption of resources at both governmental and individual level. The inflation rate rose to $26 \%$ between 1987 and 1992 . The Human Development Index of the country declined from 0.31 to 0.20 in the same period (FOS, 1992). This has put households at risk of using energy for their daily need. Kerosene and LPG that are supposed to be the major source of energy for cooking becomes unaffordable to low income households and rural populace. The consequence of this has led to change in pattern of domestic energy consumed by households in Nigeria; this has a greater consequence on the socio-economic characteristics of the poor (about $70 \%$ of Nigerians are classified as poor- earning less than a dollar per day, World Bank, 1996). It also has effect on the environment as consumption of biomass has been on the increase for households energy used for cooking on daily basis.

The major determinant of the amount and type of energy used by households in urban area is a function of population and urbanization. Research indicated that household consumption of domestic energy corroborated with "energy ladder" that implies that households consumes less costly energy and less conventional (biomass) energy, of immediate price and quality (kerosene) to more expensive highly convenient types of energy (LPG, electricity) as their income increases and or habits changes over time (Sathaye and Meyer 1990; UNCHRS, 1991; Smith, 1994) but the inflation rate has changed the whole situation as households depend on biomass to beat the effect of inflation. There has been increase in the use of kerosene among the middle and low income group in recent past (Sathaye and Meyer 1990) but the trend has changed for high consumption of charcoal due to recent increase in pump price of petroleum product in early 2012. The key factors that affect the consumption of any kind of energy in urban area by households include: the price of the energy, the availability of the energy, income and cultural preference. All these contributed to pattern of energy consumption by households. It has become an established fact that there are disparities in the energy consumed by urban households and rural households, between high and low income group; within a region, country and among countries (Takama et al, 2011). Level of urbanization, economic development and lifestyle has also been a contributing factor in the use and differences (Dzioubinski and Chipman, 1999). Urbanization influences demand for cheaper energy in Nigeria because of high level of poverty (NBS, 2011).

One of the cheapest forms of domestic energy consumption in Minna is wood fuel, because of its accessibility and availability. Many migrants from the rural areas to Minna also retain their rural habit in relation to energy use. The use of alternative energy such as kerosene, LPG and electricity are discouraged because of its non-availability, cost and inadequate infrastructure. The research by Warwick and Doig (2004) indicated that wood fuel consumption in India's urban household was 33\% of the total domestic energy use and this has no correlation with level of income, but correlates positively with LGP. But the recent removal of subsidy in Nigeria that has increase the tariffs of the alternative energy sources have return the medium income earners to traditional wood fuel consumption in Minna. Basically wood fuel is the poor man's energy source in both urban and rural setting and the demand is very high (Parisot, 1986).

Leach and Gover (1987) indicated that there is relationship between income and domestic energy consumption in India, Pakistan and Brazil; the use of biomass has decline, it was also investigated that there is positive link among income, inflation and wood fuel consumption in Ghana. The relationship shows that there is a negative correlation between income and quantity of wood fuel consumed and a positive correlation between inflation and quantity of wood fuel consumed (Abakah, 1990). Mascarenhas (1999) showed that 79\% of domestic energy use in Dar-es-salaam is with wood fuel; World Bank (1989) also proved that several cities in Senegal uses charcoal for their domestic energy. The pattern of wood fuel energy use in urban area is due to availability of the product.

\section{Study area}

The research was conducted in Minna being the capital of Niger state. The city is located in the central region of Nigeria. It is about 200km from Abuja, the Federal Capital of the Country. It has an estimated land area of about 1,000 square kilometres (Maxlock, 1980). The population of Minna over time has shown tremendous increase from 192,437 in 1991to about 300,000in 2006 (NPC, 2010). 
Minna is emerging as one of the growing cities in Nigeria with population density of 56 persons per/Km ${ }^{2}$ the growth of the city recently has been due to increase in the developmental projects embarked upon by the government and individuals in the city especially after it became the state capital. The residential land use in Minna shows three characteristics; that is high, medium and low densities with mixture of these densities except for the low density that is clearly demarcated. Many neighbourhoods of the high density found in the inner-city of Limawa, Ungwan Daji, Ungwan Kaje, Kpakungu, Bosso etc. have buildings of low quality and improper planning in the process of their development. Many of the buildings in these neighbourhoods lack accessibility due to lack of planning, the mode of accessibility has been through footpath that are narrow and not motorable. There is no adequate setback and are poorly ventilated. This area belongs to the low income earners and the few medium density for those planned by the government as residential layout such as Tunga Estate, M.I Wushishi Estate, Bosso Estate, Bosso Low cost and recently Talba Estate. The only low density area is the GRA that is characterized with high quality housing and proper layout; though there is distinction in the types of residential area but there is uniformity with each other in terms of population density, housing density, housing quality and the general neighbourhood conditions.

\section{Research Methodology}

This research was conducted in two residential areas of the identified neighbourhoods (the high and medium density) the choice of these neighbourhoods was based on the fact that the area most affected by change in economic conditions as applied by government. It has been proven that macro-economic shocks affect the poor more than the rich because of their better economic capabilities to live conveniently (Ferreira et al, 2001; Adelekan and Jerome, 2006). This is also a fact in the developing countries; there is a gulf between the rich and the poor, though both are sensitive to change in pump price of petroleum products (Leach, 1994)

The pattern of domestic energy consumption was conducted to ascertain the level of households energy use for cooking between 2000 and 2012. There is administration of questionnaire and this questionnaire consists of two sections: section A consider the socio-economic characteristics of respondents and the second section B examines the pattern and changes in energy use for cooking by households during the period and other activities that affects the energy consumption in each households. Secondary data was also used to obtain the national energy use in the country.

Four neighborhoods were sampled in high density area: Kpakungu, Limawa, Bosso Town and Barkin Sale and three neighbourhoods in medium density area: Tunga Low Cost Estate, Bosso Estate and M.I Wushishi Estate. 50 questionnaires were administered in each neighbourhood totaling 350. Most of the questionnaires were administered on women because it is their responsibility to cook for the households. Men as household heads were not used because of the antecedent of Nigerians that cooking is the sole responsibility of women.

Systematic random sampling was employed in the administration of the questionnaire to choose the respondents because of large number of housing units in the neighbourhoods; therefore, it was one household per housing unit. Quantitative data that were collected was analyzed using descriptive and inferential statistics; this was done through the use of Statistical Package for Social Scientists. The analysis was presented using frequency table, percentages, charts and graphs. The inferential statistics was used to show relationship between income and cost of domestic energy use.

\subsection{Trend in Price of Petroleum Product in Nigeria}

All the macro-economic policies of the government of Nigeria have been having effect on the price of petroleum products in the country, since the period of oil boom of late 1970s and early 1980s. Since then the price adjustment embarked upon by the government due to advise of the World Bank and IMF have had untold hardship on households intermsof the energy use by the households especially the poor. There has been increase in the price of petrol, for example from N0.60 in 1991 to about N97.00 in 2012. The trend indicated that the price was N11.00 in 1994 and was changed to N20.00 in 1998. This implies that between 1991 and 1998 there has been an increase of over 3000\%. There has been increase in price of kerosene and Liquefied Natural Gas (LPG), for example the cost of kerosene which is the major source of energy for household cooking rose from N0.40 per litre in 1991 to N6.00 in 1994 and N17.00 in 1998, it has since the advent of the democratic dispensation rose to N50.00.A 12.5kg cylinder of LPG rose from N200 in 1991 to about N3, 900.00 in 2012. Table 1 shows the rate of increase in the price of petroleum product used for domestic cooking by households. 
An Appraisal Of Household Domestic Energy Consumption In Minna, Nigeria

Table 1: Price of Petroleum Product Used for Domestic Cooking in Minna.

\begin{tabular}{|ccccc|}
\hline Year & \multicolumn{2}{c}{ Kerosene } & \multicolumn{2}{c}{ LPG } \\
& N/litre & \% change & N/litre & \% change \\
\hline 1991 & 0.40 & - & 80 & - \\
\hline 1993 & 2.75 & 587.5 & 200 & 150.0 \\
1994 & 6.00 & 118.2 & 200 & - \\
\hline 1998 & 17.00 & 183.3 & 450 & 125.0 \\
\hline 2000 & 17.00 & - & 1,000 & 122.2 \\
\hline 2002 & 24.00 & 58.3 & 1,200 & 20.0 \\
\hline 2004 & 50.00 & 34.2 & 1,500 & 25.0 \\
\hline 2008 & 50.00 & - & 2,500 & 66.7 \\
\hline 2012 & 50.00 & - & 3,900 & 56.0 \\
\hline
\end{tabular}

Source: Adapted from NNPC Annual Report, 2012.

The effect of increase in petroleum price adjustment on household poverty indicated that over $73.0 \%$ of the households in Nigeria are badly affected by the increase in the price (Tomori, 2005). This has led to households shifting from this conventional energy to non-conventional ones. The proportion of consumers using firewood for cooking purposes has increased tremendously especially in Minna where there is availability of shrubs to be cut down for charcoal and wood fuel as source of cooking in Minna due to the economic-cul-de sac. The change in the proportion of people using the charcoal and firewood in Minna is tabulated thus in table:

Table 2: Number of Households using Different Energy Source for cooking in Minna.

\begin{tabular}{|lccrrrr|}
\hline \multicolumn{2}{|c}{$\begin{array}{c}\text { Energy type } \\
\text { Low } \%\end{array}$} & Medium \% & Low \% & Medium \% & Low \% & Medium $\%$ \\
\hline Firewood & 10.0 & 4.0 & 45.0 & 25.0 & 65.0 & 54.0 \\
\hline Charcoal & 2.0 & 5.0 & 15.0 & 11.5 & 21.0 & 17.0 \\
\hline Kerosene & 84 & 60.0 & 35.0 & 30.0 & 6.5 & 15.0 \\
\hline LDG & 1.2 & 25.0 & 0.0 & 1.5 & 0.0 & 2.0 \\
\hline Electricity & 1.0 & 5.0 & 1.0 & 3.0 & 0.5 & 1.0 \\
\hline Others & 0.0 & 0.0 & 0.0 & 20.0 & 0.0 & 0.0 \\
\hline No response & 1.8 & 2.0 & 4.0 & 5.0 & 7.0 & 10.0 \\
\hline
\end{tabular}

Source: Author's Field Survey, 2012.

The analysis shows that the consumers of kerosene have shifted to the use of firewood due to the fact that they are low income earners and the increase in the price of kerosene have not allowed them to use the product often. Furthermore, it was revealed that the price of the product is not what the government place on it due to scarcity and non-availability of the product in the filling station.

The effect of the scarcity and increase in price of this conventional energy is the use of charcoal, firewood which has also increased the users and sellers of the product. There has been increase in the number of participants (both men and women) who are nowinvolved in the marketing of firewood. There has been increase in the price of firewood overtime not minding the consequential effect on the environment and users health. A bundle of firewood that cost $\$ 10$ in 1992 was sold for $\$ 50$ in 1999 and now cost about $\$ 100$ in 2012. This quantity of firewood is about enough for the cooking need of an average household in a day.

\subsection{Household Energy Consumption Pattern}

The macro-economic policies of government which was the idea of IMF that the government implemented shows that price increase of domestic energy use is felt by low and medium income group more, this is examined by considering the dynamic of household energy consumption pattern between 2000 and 2012.Table 3 above indicated the adjustment mechanism of households to the increase in the price of the petroleum product to the non-conventional energy consumption by the households. This consumption centered on firewood, charcoal, kerosene, gas, electricity etc.

\subsubsection{Consumption Pattern between 2000 and 2003}

Before and during this period, kerosene has been the major source of energy for households used in both low and medium income households because of its availability and affordability. The cost of kerosene then was between $\mathrm{N} 17.00$ and $\$ 24.00,84 . \%$ of the household surveyed in the low income group uses kerosene while $60 \%$ of the middle income also uses kerosene. This is because kerosene does not need much tending. Also the number of household in this category makes the use of kerosene a widespread. There was preference for kerosene because houses built nowadays have no kitchens. "All the landlord's concerns is that the rooms are 
completed, and those that will live in such houses have envisaged problems with the use of firewood to be too much smoke" (Adelekan and Jerome 2006).

Middle income group in this period also prefers the use of LPG (25\%) of the households surveyed; very few household consumes firewood, charcoal, electricity for cooking: though firewood is the $2^{\text {nd }}$ most important in low income area $(10.0 \%)$, the use of other sources of energy are not important during this period.

\subsubsection{Consumption Pattern between 2004 and 2008}

With the increase in the price of kerosene and LPG, household in this income group moved drastically to other sources of energy consumption apart from the kerosene and LPG. This period also shows high involvement of middlemen in the trade of kerosene which makes the product scarce and not available at the pump price. The price of kerosene jumped from $\$ 24$ to $\$ 50$ per litre and middlemen that normally have the product now sell it at the rate of $\$ 150$ per litre which is triple the pump price by the government.

The analysis shows that the proportion of household using kerosene and LPG dropped drastically to $35.0 \%$ in low income group and $30.0 \%$ in medium income group. The implication is that there are more households that use firewood and charcoal as source of domestic energy use. There has being falling down of trees in large quantities and no replacement. The percentage of the households using firewood as source of domestic energy rose from $10 \%$ in 2000 to $45 \%$ in 2008 in low income groups and from $4 \%$ in 2000 to $25 \%$ in 2008 in medium income group. The use of LPG has also changed negatively as more households are not considering it as a means of energy use.

The analysis in the table 3 indicated that the pattern of energy use by the low and medium income group change during this period as more households' resolved to the use of firewood for their domestic energy use. The use of other sources such as Electricity is on the decline. The use of hot plate for cooking by large number of household is not visible because of the amount of energy it consumes and also there has been increase in the tariff of electricity over time in Nigeria. Table 3 indicates the rate charged by the electricity company in Nigeria.

Table3: Changes in Electricity Tariff between 2000 and 2012

\begin{tabular}{ccc}
\hline Year & N/KWhr & \% change \\
\hline 2000 & 2.30 & - \\
2004 & 4.50 & 95.65 \\
2007 & 6.50 & 44.45 \\
2010 & 7.80 & 20.00 \\
2012 & 11.75 & 51.00 \\
\hline \multicolumn{3}{r}{ Source: Adapted from PHCN Record, 2012. }
\end{tabular}

Furthermore, there has being the problem of fluctuation in the voltage supply to the households and also irregularity in the supply, while some areas of the low income neighbourhoods like Kpagunku, Bakin-Sale hardly boast of 6hours electricity supply per day, and inconsistent in the time of supply has also poseda serious to be problem to the use of the electricity. It is only in few middle income neighbourhoods that the use of electricity is still practiced, though electricity will provide cheaper forms for cooking but the attendant electric shock, epileptic in supply has not encouraged its uses.

\subsubsection{Consumption Pattern between 2009 and 2012}

By 2012 when the survey was conducted the price of kerosene, LPG has risen astronomically which thereby endangered its uses. The number of households that use these sources as their main energy consumption for cooking diminishes with the price adjustment. The analysis shows that the use of firewood and charcoal has been on the increase and there is no sign of it been reduced because of the cost of these conventional energy. The percentage of households using firewood rose from $10 \%$ in 2000 to $45 \%$ in 2008 and about $65 \%$ in 2012 . This implies that more households find it difficult to use other sources and the poverty level of the country has been such that households living below poverty line are on the increase. (The report of the National bureau of statistics indicated that the national poverty index is presently at $62.5 \%$ though there is the dichotomy between the northern and southern Nigeria.)

This implies that households in Minna that fall below the poverty line are on the increase and therefore the financial resources available for use by household for domestic energy is dwindling which however encourages the use of firewood. The use of conventional energy has not been convenient and the price have skyrocketed to the extent that a litre of kerosene now costs between $\$ 150$ and $\$ 200$, which is not enough for household energy use per day. 
The proportion of household that uses firewood in both income groups rose higher and the use of kerosene reduced drastically. The use of Kerosene in low income household reduced from $84 \%$ in 2000 to about $5 \%$ in 2012 and in medium income group it reduced from $60 \%$ in 2000 to about $15 \%$ in 2012. In the low income neighbourhood the use of electricity has become non-existent. The proportion of household energy preferences is shown in the figure 1 between 2000 and 2012.

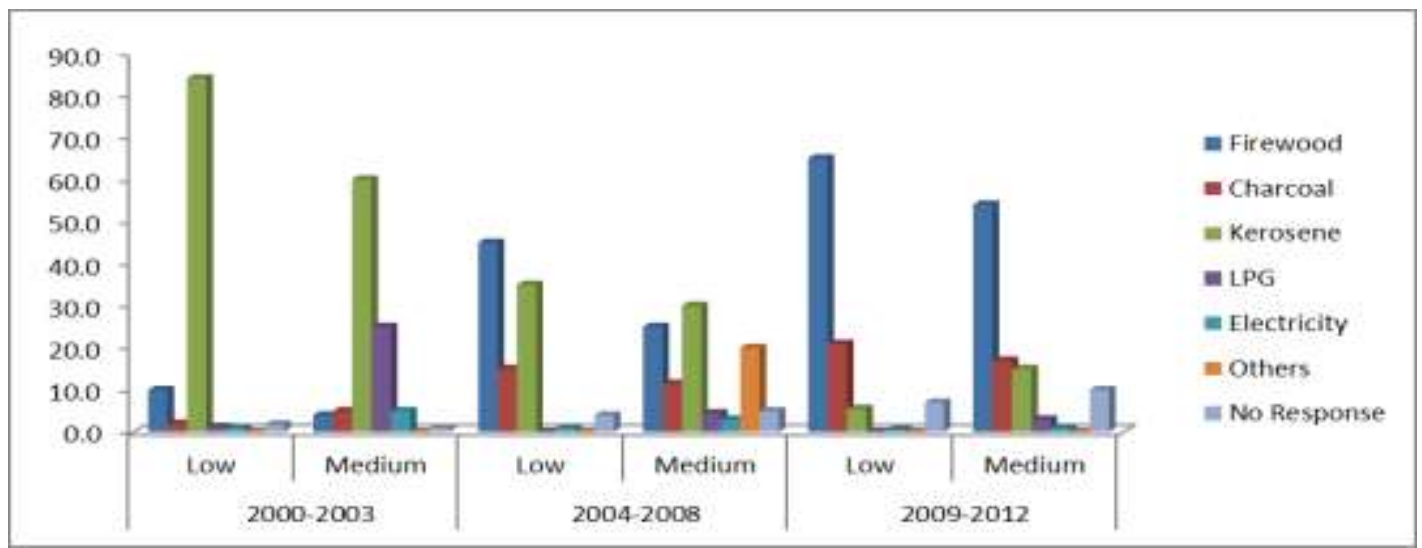

Fig. 1: Dynamic of Households Energy Consumption in Minna between 2000 and 2012.

Source: Authors Field Survey, 2012.

\subsection{Household Expenditure on Energy for Cooking}

Household have been spending money to provide necessary energy for cooking on a daily basis and because of poverty and dwindling economy the propensity of the households to spend more on domestic energy has resulted in changing from conventional to non-conventional method so as to reduce the cost of energy provision by the households. the increasing cost of kerosene has shown that between 2000 and 2012 the cost rose astronomically, from $\$ 17$ per litre to $\$ 50$ a litre in the open market, but because of non - availability and the activities of middle men has increased the price to as much as $\$ 160$ per litre at the black market. This implies that the upward review of petroleum product has increased the daily expenditure on purchase of this product. The survey indicates that households are spending more than $\$ 500 /$ daily on the provision of kerosene for cooking. This has led to the indiscriminate use of firewood and charcoal which seems cheaper and readily available. The numbers of people engaged in production and consumption of biomass has increased greatly. The analysis of the household expenditure on energy for cooking is tabulated thus in table 4.

Table4: Monthly Expenditure on Energy for Cooking by Household in Minna

\begin{tabular}{|c|c|c|c|c|c|c|}
\hline \multirow{2}{*}{$\begin{array}{c}\text { Amount } \\
(\mathbf{N})\end{array}$} & \multicolumn{3}{|c|}{ Low income } & \multicolumn{3}{|c|}{ Middle income } \\
\hline & 2000-2003 & 2004-2009 & 2009-2012 & 2000-2003 & 2004-2008 & 2009-2012 \\
\hline $1<1,000$ & 22.6 & 20.4 & 18.3 & 34.1 & 10.9 & 20.3 \\
\hline $1001-2,000$ & 70.2 & 68.6 & 70.6 & 63.3 & 64.4 & 72.6 \\
\hline $2,001-3,000$ & 6.5 & 10.5 & 9.9 & 6.6 & 20.3 & 4.6 \\
\hline \multirow[t]{2}{*}{$>3,000$} & 0.7 & 0.5 & 1.2 & 0.0 & 4.5 & 2.5 \\
\hline & 100 & 100 & 100 & 100 & 100 & 100 \\
\hline
\end{tabular}

The analysis indicated that the low income earners, those who spend about $\$ 1000$ on domestic energy for cooking has diminished from $22.6 \%$ in 2010 to $18.3 \%$ in 2012 . Also those who spend between $\$ 1000$ - $\$ 2000$ varied between $68.6 \%$ in 2004 and $70.6 \%$ in 2012. Also, those that spend between N2001 and N3000 increases to $5 \%$ in 2000 and $10 \%$ in 2004 and also those that spend more than N3000for domestic energy for cooking. The implication of this is that a most of the household resources are been spent on their daily energy need for cooking thereby increasing poverty and average amount spent on road side fast-food joints for their daily food consumption and so many households have resorted into buying of food from these fast-food joint rather than cooking because of the high cost of domestic cooking fuels.

Furthermore the expenditure of the households in medium income group on domestic energy use all shows the same characteristics with the low income earners while there was decrease in those that spends within N1000 from $34.1 \%$ in 2000 to about $20.3 \%$ in 2012;Also there has been an increase in the number of households that spend between $\$ 1000$ to N2000 on domestic energy with $63.3 \%$ in 2000 and $72.6 \%$ in 2012. Those that spend above N3000 in 2000 were initially nonexistence but have increased to $4.5 \%$ in 2004. This however increases the percentage of households that live below the poverty index. The major reason why households 
have shifted from the use of domestic fuel to alternative domestic energy source like firewood and charcoal is because of the relative cheap prices of these energy sources compared to kerosene and LPG and this is observed to be the adaptive measure developed by the various households to mitigate the impact of the high cost of domestic fuel.

\section{Discussion}

There is a direct relationship between Poverty, Energy consumption and Environment. The use of biomass fir energy is mostly used in traditional African cities and is favoured because of its cheapness and its availability. Sub-Saharan Africa, accounts for about $40 \%$ of the world hardwood (FAO, 2004). The use of fuel wood accounted for between $70 \%$ and $90 \%$ of the total consumption of domestic energy use in Nigeria today (Abd'razack and Ahmad Nazri, 2011), this corroborated the estimation of $91 \%$ of biomass been used by households in Nigeria for domestic energy consumption by Kerekezi (1999).

The consumption of any form of energy has effect on the environment though their impacts vary from lowest in LPG and highest in biomass. The loss of varieties of forest resources such as trees, animals as well as soil erosion, deforestation and desertification has emerged as environmental effect of consumption of biomass in Nigeria. About $75 \%$ of the population of Nigeria depends on this biomass for their energy use (Adelekan and Jerome, 2006). This has placed a lot of pressure on the forest resources of the country, it has been estimated that about 45,000 hectares of woodland are lost annually on this illegal felling of trees and shrubs for domestic biomass and charcoal production. If the trend continues like this, the implication is that by 2020 all the forest resources would be lost (Oladosu and Adejulugbe, 1994). One of the factors thatcause climate change is the accumulation of $\mathrm{CO}_{2}$ in the atmosphere, which is above the required atmospheric limit; this has caused the depletion of Ozone layer and created global warming. $\mathrm{CO}_{2}$ is the major contributor to the generation of greenhouse gases. The consumption of biomass has been one of the major contributors to Ecological Footprint in Nigeria (Abd'razack and Ahmad Nazri, 2012).

The use of biomass exposes women and children who are saddled with responsibility of cooking to high level of Indoor Air Pollution (IAP). The level of poverty has also led to the reduction in the type of windows been used by households because standard are not followed in the construction of dwellings, especially in the low-income neighbourhoods. The effect of this is poor ventilation which further exposes women and children to IAP. World Health Organization estimated that Africa accounts for $24 \%$ of the world IAP death in the world as related by Warwick and Doig (2004). IAP as a "killer in the kitchen" accounts for 1.6 million death globally (WHO, 1996). This call for change in household energy consumption pattern due to the effect it has on users and the environment. The consumption of biomass is fast becoming the order of the day as the cost of the alternative energy is on the increase. For example, the tariff of electricity was increased by 52\% between 2011 and 2012. This aggravates the consumption of the biomass in Minna. This has created micro climate as deforestation is highly common especially at the city fringes. There are a lot of trucks that brings in biomass to Minna every day from within and surrounding villages for domestic consumption. Various health and environmental issue in wood fuel consumption are discussed thus:

\subsection{Indoor Air Pollution}

Majority of the buildings in the selected neighbourhoods of Barkin Sale, Kpakungu and Bosso (Lowincome group) have poorly ventilated dwellings, which aggravate IAP and also the use of outdoor kitchen. The low-income neighbourhoods shows non-compliance with building regulations as buildings looked clustered without setbacks, the structures are dilapidated with inadequate spacing, though the buildings in middle-income areas of Tunga low-cost, M.I Wushishi estate shows different outlook but their characteristics are similar.

The analysis of the cooking habits of the neighbourhoods indicated that $63.3 \%$ of the low-income neighbourhood has their kitchen built in while $10.7 \%$ cooked in the kitchen detached from their dwellings, this is similar to medium-income neighbourhoods which indicated that $81.7 \%$ of the households cooked in built-in kitchens, and $8.3 \%$ in the detached kitchens. Other ways of cooking include cooking in the room, corridors etc. The analysis of cooking facilities is shown in the table 5 .

Table 5: Cooking Facilities for the Households

\begin{tabular}{llc}
\hline \multirow{2}{*}{ Cooking Facilities } & \multicolumn{2}{c}{ Income Level } \\
& Low (\%) & Medium (\%) \\
\hline Built in Kitchen & 63.3 & 81.7 \\
Detached Kitchen & 10.7 & 8.3 \\
Inside the room & 15.1 & 5.7 \\
Within the Corridor & 10.4 & 4.3 \\
\hline Total & $\mathbf{1 0 0 . 0}$ & $\mathbf{1 0 0 . 0}$ \\
\hline \multicolumn{2}{c}{ Source: Author's Field Survey, 2012 }
\end{tabular}


Cooking in the room and corridors has health implication as it aggravate IAP which exposes the households to health hazard, coupled with poor ventilation that has greater effect on their lives. Poor ventilation in majority of low-income neighbourhoods aggravates the concentration of IAP in these neighbourhoods. Other pollutants in biomass consumption include Suspended Particle Matters (SPM), CO, NO, formaldehyde and compound such as Polyaromatic hydrocarbon etc. The consumption of biomass causes the accumulation of toxic substances in the atmosphere.

Though a lots of women are not aware of the implication of consumption of biomass except the smoke and blackened pots and walls. The associated environmental and health hazard of consumption of wood fuel are thus: sore and redness of eye, burning and irritation of the body due to burning of biomass; it also lead to exhaustion, tiredness and illness as a lot of energy is required in lighting and fanning of the woods; discomfort due to heat trapped in the kitchen and smelling of clothes due to settled smoke on it among others.

\subsection{Deforestation}

The city limits which include the peri-urban have suffered greatly as deforestation has set in due to the activities of felling of shrubs and trees in Minna and its environs. The reserve forest has been depleted. Nearly all the wood fuel consumed in Minna is obtained from the peri-urban and the villages within the Minna region. There is felling of trees that are as far as $40 \mathrm{Km}$ from the city of Minna (in the villages of Essan-Nubupi, Gurara etc.) to cater for the consumption in Minna. There are more than 200 sale points identified by the research within Minna city. The majority of the consumers of the biomass purchase it from these sale points (93.5\%) while about $6.5 \%$ obtained the product directly from their farmlands. The scarcity of kerosene and its cost has also aggravated the use of biomass. There has been increase in the participation of this trade in recent time (though it has started as far back some 15 years ago). The effect of this has led to increase in the cost of measure of the product and rate of deforestation and desertification.

\section{Recommendation}

The analysis presented above is of greater importance due to incessant increase in the price of petroleum products and increase in the tariff of the electricity which makes it unaffordable for the poor people. The urban poor households use biomass for domestic cooking and heating in Minna and the sub-Saharan Africa as a whole. The National Policy on the Environment (1989) indicated that the use of energy should not have negative effect on the environment; this could be achieved by the use of environmentally friendly, safe and sustainable sources which will not be the consumption of biomass.

The pricing of petroleum product and electricity should be considered as the starting point for reduction of environmental degradation. The use of environmental related cost should be considered in the process of increasing the price of petroleum products and electricity tariff. This is because the increase in the price affects the poor more.

The supply chain of the Kerosene have to be considered so that the product will be available to lowincome households at affordable rate as easy access within the city will reduce dependency on biomass for domestic energy consumption. The problem of middlemen has to be reduced so that filling stations will have the product regularly. There is the need to keep the price of this product at a level that will make it affordable to the poor and allowing it to be stable for a longer period of time. There should be laws that will restrict the felling of trees in the forest to grow at the peri-urban area of Minna to reduce the $\mathrm{CO}_{2}$ accumulation in the city. Proper monitoring and surveillance should be entrenched to allow for compliance by the households in the city. Also there should be discouragement of the sales of biomass in the city.

Nigeria is one of the leading countries with deposit of Natural Gas (LPG) which is been flared daily. UNEP (2010) indicated that Nigeria flared up to \$1 billion of LPG annually. Though government has said that by 2008 , there will be zero tolerance to flaring, today the situation persists. If the use of LPG is encouraged at lower price, it will encourage the middle-income households to use it. Government has to ensure the use of clean, energy-efficient LPG for cooking in the country to reduce dependence on biomass by the populace. This could be achieved in conjunction with private sector and subsidy for the use of the product.

The production of LPG stove to replace bio-fuel stove and expansion and distribution network of this product will also encourage the use of this product. Housing and household energy consumption determines the level of exposure to IAP; therefore there is need for building standard to be enforced. The ventilation, kitchen type and setbacks have to be strictly adhered to.

\section{Conclusion}

This research was conducted to evaluate he pattern of household domestic energy consumption within different neighbourhoods and income level in Minna because of subsidy regime issues in Nigeria. The analysis indicated that over the years, the consumption of biomass has been on the increase due to its cheapness, availability, traditional affinity, while the consumption of alternative, clean, safer, environmental friendly and 
sustainable ones are dwindling. The analysis indicated that there is significant relationship between choice of energy and income as well as between energy use and household size.

In the late $20^{\text {th }}$ century, the use of Kerosene was favoured by low income households in Minna while the medium and high income households depend on conventional energy sources, but as the years roll by to early $21^{\text {st }}$ century the trend changed and the use of biomass has been on the increase due to price changes of the conventional sources.

The increase in the price of LPG, Kerosene and Electricity tariff has dropped the number of households using these sources so as to reduce their expenditure on domestic energy use. There has been increase in the number of households using biomass as source of cooking in Minna. The reduction in the frequency of cooking has been used as a strategy for energy consumption so as to reduce cost of domestic energy use. The change in energy consumption types can be related to income level, poverty and the affordability of different types of sources. The survey shows that the trend of the use of biomass will continue except urgent and proactive measures are put in place to change the consumption pattern and income of the households in Minna.

\section{References}

[1]. Abd'razack, Nelson T.A and Ahmad Nazir bin M. L (2012): Benchmarking Sustainability and Ecological Footprint of African cities. Book of Proceedings of SEATUC Conference, Bangkok, Thailand. March.

[2]. Abakah, E.M.(1990): Real Incomes and Consumption of Wood fuels in Ghana. Energy Economics 12(3) $227-231$.

[3]. Adelekan, I.O and Jerome, A.T (2006): Dynamics of Household Energy Consumption in a Traditional African City, Ibadan.Environmentalist.Springer ScienceBusiness Media. LLC. 26 99-110. DOI 10.1007/s10669-006-7480-2

[4]. Alabe, M. (1996): Household Energy Consumption Patterns in Nigeria. Energy for Sustainable Development 2(5) 42-45.

[5]. Clancy, J.S (2008): Urban ecological Footprint in Africa. Afr. J. Eco. 46(2): 463-470

[6]. Dzioubinski, O and Chipman, M (1999): Trend in Consumption and Production: Household Energy Consumption. DESA discussion paper Number 6.

[7]. Ferreira, F., Prennushi, G and Ravallion, M. (2001): Protecting the Poor from Macro-economic Shock. An Agenda for Action in Crisis and Beyond.World Bank Washington D.C.

[8]. Federal Office of Statistics (FOS, 1992): National Integrated Survey of Households. Report of General Household Survey. Lagos Nigeria.

[9]. GFN (2010): Ecological Footprint Atlas. GFN Publishers. Oakland California. USA available at www.footprintnetwork.org. Retrieved on $25^{\text {th }}$ April.

[10]. Karekezi, S. (1999): Access to Modern Energy-A View from Africa in "Energy after the Financial Crisis: Energy and Development Report 1999”. Washington, World Bank.

[11]. Leach, G. (1987): Energy and the urban Poor. IDS Bulletin 18(1), 31-38. Institute of Development Studies, Sussex.

[12]. Leach, G. and Gower, R. (1988); Beyond the Wood Fuel Crisis: People, Land and Trees in Africa. Earthscan Publishers. London

[13]. Leach, M. (1994):Rainforest Relations: Gender and Resource Use Among the Mende of Gola, Sierra Leone, Edinburgh University Press, Edinburgh.

[14]. Maxlock, (1980): Final Draft copy of Minna Masterplan. Maxlock Publishers, Maiduguri. Nigeria.

[15]. Morenikeji, O.O, Sanusi, Y.A., and Jinadu, A.M. (2006): Economic and Environmental Implication of Fuel wood Trade and Consumption in Niger State. Futminna Monograph Series .FUT/UBR/SET/No. 3. Federal University of Technology, Minna, Nigeria.

[16]. National Bureau of Statistics (2011): Poverty Index in Nigeria. NBS Publication, Presidency, Abuja. Nigeria.

[17]. National Population Commission, (2010): Priority Tables for 2006 Population and Housing Census. NPC Publications, Presidency Abuja

[18]. Ojo, M.O (1989): An Appraisal of the socio-Economic Impact of SAP Policies in Nigeria. Economic and Financial Review. CBN. Lagos. Nigeria.

[19]. Oladosu, G.A. and Adegbulugbe, A.O. (1994): Nigeria's Household Energy Sector: Issues and Supply/Demand frontiers. Energy Policy.22(6) 538-549.

[20]. Parisot, R. (1986): Environmental Impact of Food and Energy Production in India. Paper Presented for the Food Energy News Programme of the United Nation University, Tokyo.

[21]. Sathaye, J and Meyer, S.(1990): Urban Energy Use in Developing Countries: A Review. Cited in Desai, A.V.(ed): Pattern of Energy use in Developing Countries. IDRC and UNU Willey Eastern Limited New Delhi.

[22]. Smith, K.R. (1994): Air Pollution and the Energy Ladder in Asian Cities. The International Journal of Energy.18(5).

[23]. Takama, T., Lambe, F., Johnson, F.X., Arvidson, A., Atanasov, B., Debebe, M., Nilsson, L., Tella, P., and Tsephel, S.A (2011): Will African Consumers Buy Cleaner Fuel and Stoves? Stockholm Environment Institute. Research Report. April. Available at Www.sei-international.org

[24]. UNCHS (Habitat) (1991): Use of Energy by Households and in Construction and Production of Building Materials. Theme paper presented to the thirteenth session of the commission on human settlements Harare, Zimbabwe, 29 April - 8 May, 1991.

[25]. UNCHS (Habitat)(1996):An Urbanizing World: Global Report on Human Settlements. Oxford University Press. Oxford.

[26]. UNPFA (2007): State of the World Population Report. Available at www.unfpa.org/swp/2007.Retrieved on $24^{\text {th }}$ Feb.

[27]. UN-Habitat (2008): State of the World Population: Hamonious Cities. Oxford University Press. Oxford.

[28]. Warwick, H. and Doig, A. (2004):Smoke-the Killer in the Kitchen, ITDG Publishing, London.

[29]. World Bank/UNDP: 1989, Senegal: Urban Household Energy Strategy, ESMAP Report No. 96/89. 